\title{
HUMAN BUILDING. CONSTRUIR PARA Y CON LAS PERSONAS. Conclusiones a PARTIR de CINCO CASOS DE ESTUdio
}

\author{
Human building. Settlements for and from People.
} Conclusions on Six Case-Studies

\section{Sara Márquez Martín \\ sarammrowe@gmail.com \\ Arquitectura Sin Fronteras}

RESUMEN: El presente artículo propone la definición del concepto de human building como una actitud frente a la arquitectura, el urbanismo y el diseño que implica que, como profesionales somos, ante todo, personas que construimos espacios para y con las personas.

A través del análisis a posteriori de las experiencias y trabajo de campo recogido por la autora como arquitecta, cooperante y enseñante en tres continentes y en seis casos de estudio, se plantea cómo puede la actitud ante la profesión tener un impacto eco-social sobre la realidad que se construye.

Se observa el significado de vivir y trabajar para y con las personas, los componentes de la actitud y procesos participativos. Dichos procesos incluyeron: construcción comunitaria, técnicas adecuadas para cualquier edad y género, uso de materiales naturales y técnicas vernáculas, gestión de proyectos orientada a personas, derecho a la ciudad y a los asentamientos rurales, apropiación de las técnicas constructivas (belleza e identidad) y transferencia tecnológica.

Se concluye que en los casos de estudio la empatía y el disfrute facilitaron la confianza en las negociaciones, los acuerdos y la coherencia ante los compromisos. Esas decisiones participativas potenciaron la apropiación de los procesos.

Se propone replicar los resultados en tanto que en los casos analizados, las personas y ecosistemas se vieron beneficiados, tomando la actitud como elemento horizontal que conecta un mundo complejo para hacer los asentamientos humanos más humanos. 
PalABras ClaVe: human building, participación, asentamientos humanos, actitud, cooperación al desarrollo.

ABSTRACT: This article is a cross-curricular proposal that defines human building as an attitude to architecture, urbanism and design which implies that, as professionals, first and foremost we are people who build living spaces with and for other people. Through an analysis of the author's experience and field work in six case studies on three continents, we consider how attitude can affect the eco-social influence the building profession has on what is constructed.

The article explores the meaning of working and living with and for people, the components of attitude and participatory processes. The processes presented include building as a community, techniques adapted to all ages and genders, use of natural materials and vernacular techniques, people-focused, process-oriented project management (participation), right to the city and rural settlements (place making), appropriation of the building process (beauty and identity), knowledge sharing, and technological transfer.

The conclusion drawn from the case studies is that empathy and enjoyment fostered stakeholders' trust during negotiations, agreements and later coherence with what was agreed. These participative decisions strengthened the appropriation of the process. In the cases studied, personal mindset and social conscience promoted an attitude that was beneficial to both people and ecosystems. Attitude can be the common thread that connects a complex world to make human settlements more humane.

KEYWORDs: human building, participation, human settlements, attitude to change, development cooperation.

RESUM: El present article proposa la definició del concepte de human building com una actitud davant l'arquitectura, l'urbanisme i el disseny que implica que, com a professionals som, abans que res, persones que construïm espais per $\mathrm{i}$ amb les persones. 
A través de l'anàlisi a posteriori de les experiències i treball de camp recollit per l'autora com a arquitecta, cooperant i ensenyant en tres continents i en sis casos d'estudi, es planteja com pot l'actitud davant la professió tenir un impacte eco-social sobre la realitat que es construeix.

S'observa el significat de viure i treballar per i amb les persones, els components de l'actitud i processos participatius. Aquests processos van incloure: construcció comunitària, tècniques adequades per a qualsevol edat i gènere, ús de materials naturals i tècniques vernacles, gestió de projectes orientada a persones, dret a la ciutat $i$ als assentaments rurals, apropiació de les tècniques constructives (bellesa i identitat) i transferència tecnològica.

Es conclou que en els casos d'estudi l'empatia i l'esbarjo van facilitar la confiança en les negociacions, els acords i la coherència davant els compromisos. Aquestes decisions participatives van potenciar l'apropiació dels processos.

Es proposa replicar els resultats en tant que en els casos analitzats, les persones i ecosistemes es van veure beneficiats, prenent l'actitud com a element horitzontal que connecta un món complex per fer els assentaments humans més humans.

Paraules Clau: human building, participació, assentaments humans, actitud, cooperació al desenvolupament. 


\section{Introducción}

El presente artículo aborda una reflexión sobre la actitud ante la profesión de construir realizada a partir del análisis a posteriori del trabajo de campo desarrollado por la autora en calidad de arquitecta, enseñante y cooperante entre octubre de 2010 y enero de $2017 .^{1}$

El análisis de la actitud de los actores involucrados en los casos conduce a la definición de human building como una actitud frente a la arquitectura, el urbanismo y el diseño que implica que, como profesionales somos, ante todo, personas que construimos espacios para y con las personas.

Esta actitud se enmarca en el contexto de la «Nueva Agenda Urbana» aprobada durante la conferencia HABITAT III (Organización de las Naciones Unidas, 2016) que defiende no dejar a nadie atrás. Esta inclusión universal todas las personas del planeta tendrán derecho a la ciudad — no puede avanzar ignorando los límites ecológicos del planeta. Se propone, además, un enfoque más inclusivo que contemple los asentamientos humanos tanto en ciudades como en áreas rurales.

A través del estudio de los seis casos se identifica los elementos de la actitud que tuvieron un impacto positivo tanto en los procesos como en los resultados de los proyectos de diseño, construcción y mantenimiento de asentamientos humanos (fig. 1).

El texto se articula en: introducción, método, resultados, discusión de los mismos y conclusión. El método incluye una breve presentación de los casos y descripción de lo que supone vivir y trabajar para y con las personas. Los resultados analizan la actitud ante la profesión. La discusión de los resultados se centra en la toma de decisiones en los procesos participativos y en la definición de estrategias eco-sociales para proyectos de desarrollo. Por último, la conclusión plantea cómo y por qué replicar la actitud definida como human building en nuevos proyectos.

1. Se adelantan lugares y fechas de los seis casos que serán presentados con detalle en el artículo: Escuela Taller la Guaira, Venezuela, 2010; Oficina Técnica de Cooperación de Niamey, Niger, 2011; Centro Cultural de España, Guatemala, 2012; Programa VACA de autoconstrucción en comunidades rurales de México e India, 2013-2016; Ministerio de Obras Públicas de Mozambique, 2014-2017; Barrios informales de Maputo, Mozambique, 2017. 
Los casos no se analizarán con el mismo detalle, sino que de cada uno se destacarán exclusivamente los factores que ayuden a definir el objeto de estudio respondiendo a la siguiente pregunta: ¿cómo puede la actitud human building ante la profesión de la arquitectura y el urbanismo tener un impacto eco-social sobre la realidad que construimos?

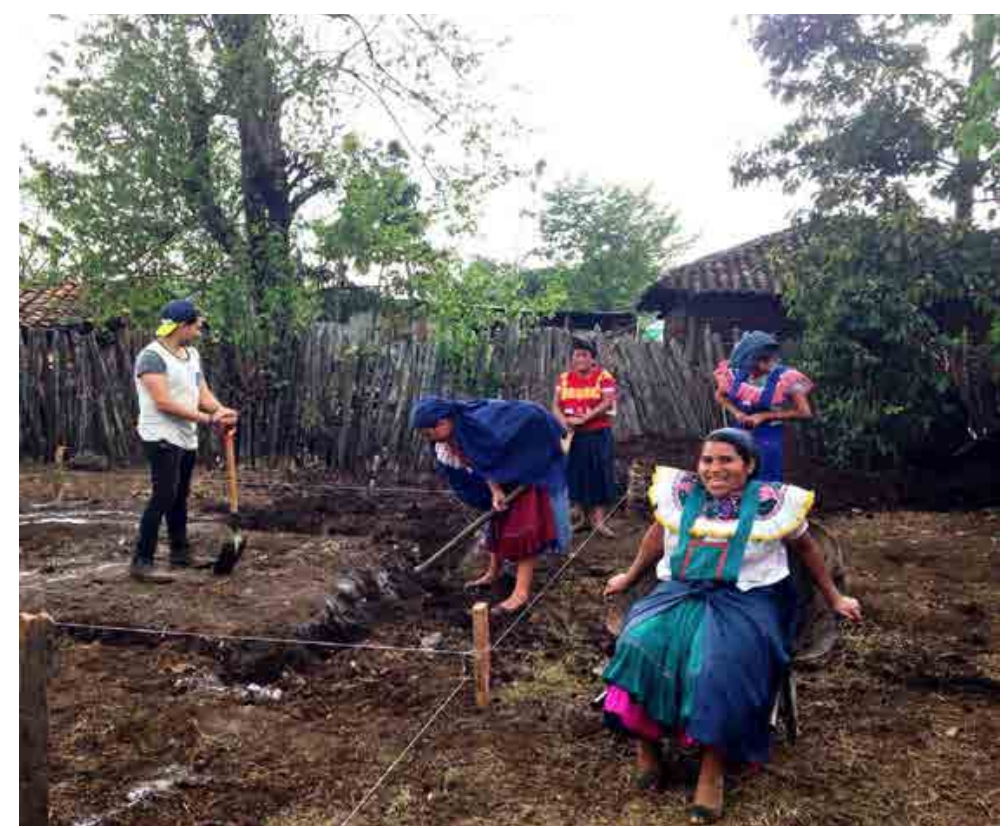

Figura 1. Programa vaca. Disfrutando del inicio de las obras de construcción del Centro Colectivo de Mujeres y Maíz en Amatenango del Valle, 2016.

\section{Método}

\subsection{Presentación de los casos}

Los casos de estudio están englobados en el campo de la cooperación al desarrollo y el bien común, social good (fig. 2). El ámbito de actuación de los proyectos han sido tanto instituciones gubernamentales como organizaciones de la sociedad civil (OCB).

Los casos ligados a instituciones gubernamentales son la Embajada de España en Níger, el Centro Cultural de España en Guatemala, el Ministerio de Obras Públicas de Mozambique y agencias de cooperación al desarrollo bilateral - la Agencia Española de Cooperación Internacional al Desarrollo 
(AECID) con sus oficinas técnicas de cooperación (OTC) en Níger, Venezuela y Guatemala y la Cooperación Alemana (GIZ) con su programa de Buena Gobernación Financiera en Mozambique.

Los casos ligados a OCB son la Escuela Taller la Guaira en Venezuela, la Demarcación de Cataluña de Arquitectura Sin Fronteras (ASF) — ONG española responsable de defender el derecho al hábitat - y el programa VACA cofundado en México en 2013 por Juan Carlos Loyo y la autora. Este último que responde a las siglas de: Verano, Aprende, Construye y Ayuda, es una plataforma de construcción comunitaria en áreas rurales con materiales naturales y técnicas vernáculas. ${ }^{2}$

Algunos casos han sido live projects ${ }^{3}$ como el programa VACA, otros casos son proyectos de cooperación al desarrollo formulados y ejecutados siguiendo diferentes métodos de gestión. ${ }^{4}$

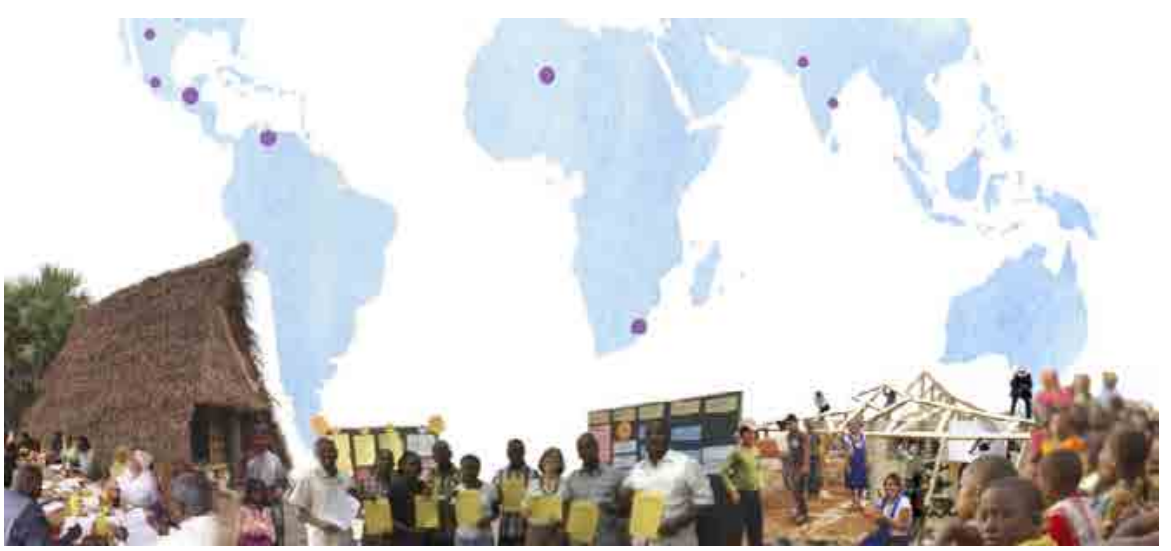

Figura 2. Mapa de los proyectos. Fuente: autora, 2017.

En el artículo se observarán sólo los elementos de los siguientes casos que ayuden en la definición de human building. Para facilitar la comprensión glo-

2. https://programavaca.wordpress.com/ https://humanbuilding.es

3. Live projects es un concepto que está definiendo la Universidad Oxford Brookes que propone situaciones en las que los estudiantes se vean implicados en proyectos (presupuesto, negociación y ejecución) que benefician mutuamente a comunidades y al desarrollo del propio estudiante (Anderson + Priest, Oxford Brookes University, 2012). Ver http://architecture.brookes.ac.uk/liveprojects/

4. Los proyectos de cooperación al desarrollo siguen diferentes métodos de gestión como: el marco lógico, gestión por resultados, Capacity Works, sale del alcance de este artículo caracterizarlos o definirlos. Se ha considerado a la hora de analizar la actitud de los actores participantes. 
bal de cada caso y los elementos analizados a lo largo del artículo se presenta la siguiente tabla resumen (tabla 1).

\section{Tabla 1.}

\section{Presentación de los casos}

\begin{tabular}{|c|c|c|c|c|c|c|}
\hline & CAMPOS & LUGAR & INSTITUCIÓN & $\begin{array}{l}\text { PERSONAS INVO- } \\
\text { LUCRADAS }\end{array}$ & $\begin{array}{l}\text { RESPONSABILIDAD } \\
\text { DE LA AUTORA }\end{array}$ & $\begin{array}{l}\text { FACTOR DE } \\
\text { LA ACTITUD } \\
\text { ANALIZADO }\end{array}$ \\
\hline $\begin{array}{l}2010- \\
2011\end{array}$ & $\begin{array}{l}\text { Enseñanza } \\
\text { técnica (teóri- } \\
\text { co-práctica): } \\
\text { Patrimonio. } \\
\text { Restauración. }\end{array}$ & $\begin{array}{l}\text { La Guaira, } \\
\text { Venezuela. } \\
\text { Barriadas } \\
\text { del puerto } \\
\text { de Caracas. } \\
\text { Zona urbana } \\
\text { portuaria, } \\
\text { tugurios. }\end{array}$ & $\begin{array}{l}\text { ОСв } \\
\text { Escuela taller } \\
\text { La Guaira }\end{array}$ & $\begin{array}{l}\text { Jóvenes que } \\
\text { abandonan la } \\
\text { enseñanza secun- } \\
\text { daria en entornos } \\
\text { vulnerables (nar- } \\
\text { cotráfico, desem- } \\
\text { pleo, violencia, } \\
\text { etc.). }\end{array}$ & $\begin{array}{l}\text { Profesora de Patri- } \\
\text { monio. } \\
\text { Jefa de Obras de } \\
\text { Restauración Patri- } \\
\text { monial. }\end{array}$ & $\begin{array}{l}\text { Ejemplos de } \\
\text { vivir y trabajar } \\
\text { para y con las } \\
\text { personas. }\end{array}$ \\
\hline $\begin{array}{l}2011- \\
2012\end{array}$ & $\begin{array}{l}\text { Gestión de } \\
\text { Proyectos: } \\
\text { Cultura para } \\
\text { el desarrollo. }\end{array}$ & $\begin{array}{l}\text { Niamey, } \\
\text { Níger. } \\
\text { Zona en } \\
\text { proceso de } \\
\text { urbaniza- } \\
\text { ción. }\end{array}$ & $\begin{array}{l}\text { Inst. Guber. } \\
\text { OTC de Níger. } \\
\text { AECID }\end{array}$ & $\begin{array}{l}\text { Niños y jóve- } \\
\text { nes de Niamey } \\
\text { (pobreza extrema, } \\
\text { malnutrición). } \\
\text { Artistas. } \\
\text { Gestores cultu- } \\
\text { rales. }\end{array}$ & Gestora Cultural. & $\begin{array}{l}\text { Ejemplos de } \\
\text { vivir y trabajar } \\
\text { para y con las } \\
\text { personas. } \\
\text { Procesos } \\
\text { participativos: } \\
\text { revisión de } \\
\text { compromisos. }\end{array}$ \\
\hline $\begin{array}{l}2012- \\
2013\end{array}$ & $\begin{array}{l}\text { Construcción } \\
\text { Gestión de } \\
\text { proyectos: } \\
\text { Restauración/ } \\
\text { Rehabilitación. } \\
\text { Cultural para } \\
\text { el desarrollo. }\end{array}$ & $\begin{array}{l}\text { Ciudad de } \\
\text { Guatemala. } \\
\text { Recualifi- } \\
\text { cación de } \\
\text { Centro } \\
\text { Histórico. }\end{array}$ & $\begin{array}{l}\text { Inst. Guber. } \\
\text { Centro Cultu- } \\
\text { ral de España } \\
\text { en Guatemala. }\end{array}$ & $\begin{array}{l}\text { Artistas. } \\
\text { Obreros. } \\
\text { Arquitectos. }\end{array}$ & $\begin{array}{l}\text { Gestora Cultural. } \\
\text { Directora de Obra. }\end{array}$ & $\begin{array}{l}\text { Ejemplos de } \\
\text { vivir y trabajar } \\
\text { para y con las } \\
\text { personas. } \\
\text { Empatía. }\end{array}$ \\
\hline $\begin{array}{l}2013- \\
2016\end{array}$ & $\begin{array}{l}\text { Diseño. } \\
\text { Construcción. } \\
\text { Enseñanza } \\
\text { técnica:Auto- } \\
\text { construcción } \\
\text { asistida en } \\
\text { comunidades } \\
\text { rurales. } \\
\text { Técnicas } \\
\text { vernáculas. } \\
\text { Uso de mate- } \\
\text { riales natu- } \\
\text { rales. }\end{array}$ & $\begin{array}{l}\text { México e } \\
\text { India. } \\
\text { Zonas } \\
\text { periurbanas } \\
\text { y rurales. }\end{array}$ & $\begin{array}{l}\text { OCB } \\
\text { Programa VACA. }\end{array}$ & $\begin{array}{l}\text { Ejidatarios. } \\
\text { Colectivos de } \\
\text { mujeres. } \\
\text { Cooperativas de } \\
\text { mujeres indígenas. } \\
\text { Comunidad men- } \\
\text { dicantes. } \\
\text { Voluntarios. } \\
\text { Comunidad acadé- } \\
\text { mica Equipo VACA. }\end{array}$ & $\begin{array}{l}\text { Cofundadora. } \\
\text { Directora. }\end{array}$ & $\begin{array}{l}\text { Ejemplos de } \\
\text { vivir y trabajar } \\
\text { para y con } \\
\text { las personas. } \\
\text { Caracteri- } \\
\text { zación del } \\
\text { grupo bene- } \\
\text { ficiario del } \\
\text { proyecto. } \\
\text { Empatía. } \\
\text { Procesos par- } \\
\text { ticipativos. } \\
\text { Intención. } \\
\text { Factores } \\
\text { replicables. }\end{array}$ \\
\hline
\end{tabular}




\begin{tabular}{|c|c|c|c|c|c|c|}
\hline $\begin{array}{l}2013- \\
2017\end{array}$ & $\begin{array}{l}\text { Legislación: } \\
\text { Operacionali- } \\
\text { zación de Polí- } \\
\text { tica Pública } \\
\text { de Manteni- } \\
\text { miento de } \\
\text { Edificios }\end{array}$ & $\begin{array}{l}\text { Inhambane } \\
\text { y Maputo } \\
\text { en Mozam- } \\
\text { bique. } \\
\text { Edificios } \\
\text { Públicos. }\end{array}$ & $\begin{array}{l}\text { Inst. Guber. } \\
\text { Ministerio de } \\
\text { Obras Públicas } \\
\text { de Mozambi- } \\
\text { que. }\end{array}$ & $\begin{array}{l}\text { Funcionarios públi- } \\
\text { cos del área de la } \\
\text { construcción. }\end{array}$ & $\begin{array}{l}\text { Asesora de Obras } \\
\text { Públicas. }\end{array}$ & $\begin{array}{l}\text { Ejemplos de } \\
\text { vivir y trabajar } \\
\text { para y con las } \\
\text { personas. } \\
\text { Factores } \\
\text { cognitivos, } \\
\text { afectivos y } \\
\text { conductuales } \\
\text { de la actitud. } \\
\text { Motivación. }\end{array}$ \\
\hline 2017 & $\begin{array}{l}\text { Construcción. } \\
\text { Legislación: } \\
\text { Recualificación } \\
\text { urbana de } \\
\text { barrios infor- } \\
\text { males. } \\
\text { Derecho a la } \\
\text { ciudad. } \\
\text { Movilidad } \\
\text { y espacio } \\
\text { público. }\end{array}$ & $\begin{array}{l}\text { Maputo, } \\
\text { Mozambi- } \\
\text { que. } \\
\text { Zonas urba- } \\
\text { nas infor- } \\
\text { males. }\end{array}$ & $\begin{array}{l}\text { OCB } \\
\text { Arquitectura } \\
\text { sin Fronteras } \\
\text { ASF. }\end{array}$ & $\begin{array}{l}\text { Familias de barrio. } \\
\text { Estudiantes de } \\
\text { cartografía. } \\
\text { Funcionarios } \\
\text { municipales. } \\
\text { Equipo multidisci- } \\
\text { plinar ASF. } \\
\text { Abogados volun- } \\
\text { tarios. }\end{array}$ & $\begin{array}{l}\text { Coordinadora de } \\
\text { proyectos. } \\
\text { Arquitecta. }\end{array}$ & $\begin{array}{l}\text { Ejemplos de } \\
\text { vivir y trabajar } \\
\text { para y con } \\
\text { las personas. } \\
\text { Caracteri- } \\
\text { zación del } \\
\text { grupo bene- } \\
\text { ficiario del } \\
\text { proyecto. } \\
\text { Dignidad y } \\
\text { seguridad. } \\
\text { Factores } \\
\text { replicables. }\end{array}$ \\
\hline
\end{tabular}

Fuente: elaboración propia, 2017.

\subsection{Vivir y trabajar para y con las personas}

\subsubsection{Concepto de vivir y trabajar para y con las personas}

En cada uno de estos proyectos se trabajó para y con las personas (fig. 3). La actitud cultivada en todos los casos supone no sólo que el objetivo de cada proyecto son las personas sino, además, que ellas están implicadas activamente en todas sus fases. A diferencia de procesos orientados al lucro o a los resultados, cuando el objeto y sujeto son las personas, la apropiación de los procesos es más probable.

\subsubsection{Aplicación en los casos}

En Niamey se preparó la agenda cultural para y con artistas y gestores culturales. En Kaliyanpoondi se diseñaron y construyeron viviendas para y con sus moradores. En Inhambane y Maputo se realizó un trabajo de asesoramiento para la operacionalización de una política pública, para y con 
los funcionarios públicos. En La Guaira se restauraron edificios patrimoniales para y con los estudiantes mientras aprendían oficios — carpintería, forja, albañilería, hostería y electricidad- En Ciudad de Guatemala se rehabilitó un antiguo cine en centro cultural con y para los artistas. En Maputo se está definiendo el plan parcial del barrio de Chamanculo con y para sus habitantes.

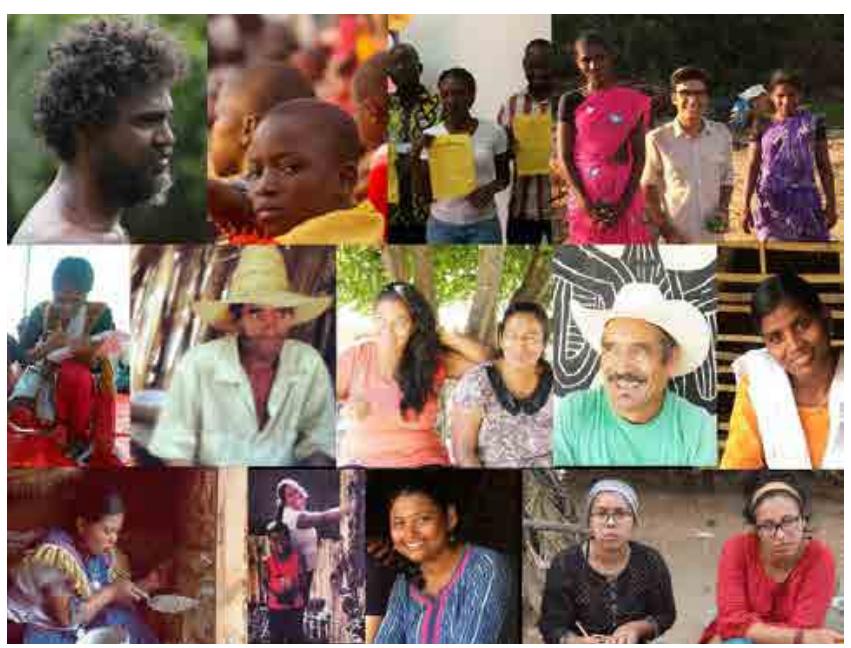

Figura 3. Vivir y trabajar para y con las personas. Fuente: autora, 2017.

\subsubsection{Factores que dificultan abordar proyectos para y con personas: definición y caracterización de las personas}

Es recurrente enfocar la realidad habitacional desde un punto de vista sólo urbano desde que en 2008 la población mundial que vivía en zonas urbanas superó a la que vivía en zonas rurales (Organización Naciones Unidas-UNFPA, 2007). Sin embargo, el $48 \%$ de la población todavía sigue viviendo en áreas rurales (World Bank, 2015). Es cierto que hay regiones donde la relación es $80 \%$ urbano frente a $20 \%$ rural, pero esas cifras no dejan de ser medias matemáticas. La continua migración a las ciudades no responde a que sean espacios de oportunidad sino a que las áreas rurales han quedado marginadas. Invisibilizar las áreas rurales dificulta pensar, diseñar y construir asentamientos humanos en ellas. Para no dejar a nadie atrás es fundamental salir de las cifras y de las abstracciones y por un momento pensar que como profesionales construimos para las personas. Cada una de ellas vive una realidad.

La cooperación al desarrollo, en un continuo ejercicio de depuración para alcanzar la corrección política, cambia la forma en la que define a las personas 
que participan en los proyectos. Sólo para imaginar y formular los proyectos se realizan ejercicios de abstracción en los que cualificamos y caracterizamos a las personas con las que vivimos y trabajamos: beneficiarios directos o indirectos, donantes, actores (tipos de actor del proyecto); comunidades rurales, comunidades mendicantes, colectivos de mujeres, jóvenes vulnerables (tipos de actor por su oficio, localización, edad, género, tipos de capacidad, etc.).

Sería pertinente, por tanto, no hacer referencia a «jóvenes que abandonan la enseñanza secundaria en entornos vulnerables» sino a Yorlai o a Javier en La Guaira; o a «funcionarios públicos» sino a Massingue o Wache en Inhambane; o a «colectivos de mujeres indígenas» sino a Xunca, Tiburcia, Hermelinda o Juanita en Chiapas; o a «comunidades mendicantes» sino a Kupan o Sarasu; o a «voluntarios» sino a Alejandro o Sarai. Esto sin hacer mención a las personas que han participado de los proyectos sin ser beneficiarias directas del objeto construido: Sarala, Luci, Lunes, Juan Antonio, Helen, Sandra, Esperanza, Dona Pe, Dolly, Liz, Pedrito, Salvi, Gorka, Taremba, Carolina, Antonio, Ousmane, David, Fátima, Alejandro, Jean Paul, Katharina, Ponnan, Peter, Reinaldo, Ana, Hamilton, Silvia, Joaquín, el fallecido Dr. Garza, Juanón, María, Amaya, Teresa y tantos otros.

Cuanto más grande es el proyecto, mayor es la abstracción y la necesidad de cifras a la hora de formular las intervenciones. Sería imposible mencionar cada vez a todos los miembros de las 713 familias con la que Arquitectos Sin Fronteras trabaja actualmente en Maputo. El proyecto afecta a cada una de ellas, la dimensión no permite mencionarlas pero sí trabajar para y con ellas. Trabajar y vivir para y con las personas no implica no poder abstraer cuando nos enfrentamos a formular proyectos. Implica saber cuándo abstraer para que los proyectos avancen y cuándo involucrar a cada una de las personas. No dejar a nadie atrás en las decisiones.

Cuanto más concreto y local es el proyecto las personas se involucran más. Por ejemplo, en Amatenango del Valle, las mujeres del colectivo «Mujeres y maíz» participaron con mayor facilidad en la construcción de sus espacios productivos y centro comunitario que los funcionarios públicos en Maputo en la operacionalización de su política pública. La motivación de las mujeres frente a construir su espacio era mayor en tanto que era más fácil imaginar el 
resultado. Además, las mujeres construían sus espacios productivos mientras que los funcionarios trabajaban para el patrimonio del estado.

\subsubsection{Cooperantes o facilitadores de proyectos para y con las personas}

Aunque parezca obvio, entre las personas para y con quienes trabajamos están quienes facilitan los procesos. En los proyectos de cooperación se corre el riesgo de auto-esclavizarse para lograr los objetivos de cada proyecto, y ambas realidades no se deben perder de vista (fig. 4).

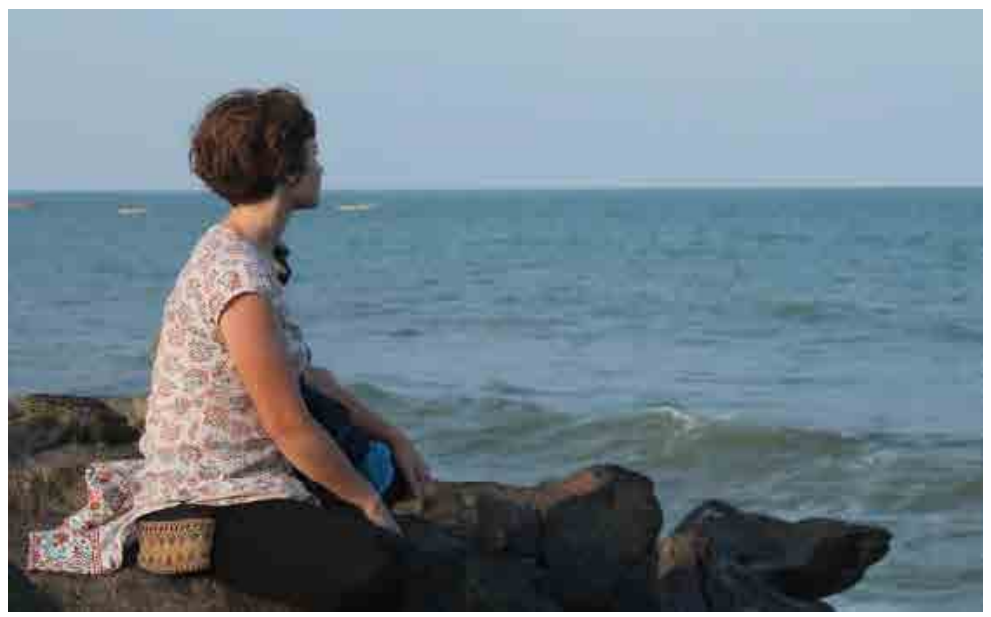

Figura 4. Entre las personas para y con quien trabajamos estamos nosotros mismos. Fuente: Alejandro Álvarez, 2017.

Presentados los casos y caracterizado lo que supone vivir y trabajar para y con las personas cabe preguntarse: ¿cómo puede la actitud ante la profesión tener un impacto eco-social sobre la realidad que construimos?

\section{Resultados}

\subsection{Actitud ante la profesión de construir asentamientos urbanos}

\subsubsection{Definición de actitud y sus componentes}

Desentrañar el concepto de actitud, su medición y estudio queda fuera de este artículo, sin embargo, es pertinente entender cómo la actitud afecta a 
la profesión de construir espacios habitables, teniendo en cuenta dentro del ámbito de la profesión tanto diseño como construcción, mantenimiento, enseñanza, legislación y gestión de proyectos.

Para analizar el rol que tiene la actitud en la profesión es importante entender, antes, cómo afecta en el día a día. De acuerdo con el estudio de Briñol, Falces y Becerra (2007) la actitud dirige la atención, pensamientos y conductas y contribuye a satisfacer las necesidades psicológicas fundamentales de los humanos. Rajvinder Samra (2014) analiza el estudio de la actitud recogiendo tres componentes: uno cognitivo, otro afectivo y otro conductual, que en el campo de acción se traducen como entender la información (pensamiento y creencias), sentir identidad y vivir en valores y actuar en consecuencia de los anteriores.

\subsubsection{Análisis de los componentes de la actitud en el caso de la opera-} cionalización de una política pública en Mozambique

Al analizar el proyecto destinado a operacionalizar la política pública de mantenimiento de edificios en Mozambique (fig. 5), se aclara el papel de la actitud y sus tres componentes. En este enfoque transformador, la relación de asesoría establecida con los funcionarios implicaba que, a diferencia de una asistencia técnica, en lugar de realizar, se acompañaba a quienes realizaban, fortaleciendo sus capacidades. Teóricamente esto garantiza la apropiación del proceso por parte de una institución y refuerza las habilidades de quienes trabajan ahí. En la práctica supone un equilibrio, entre acompañar, hacer, esperar, percibir resultados, esperar, cambiar, aceptar, hacer, facilitar, motivar, etc. Si se añade el factor de diferencias culturales, la ecuación se hace más compleja. Una posible solución para facilitar su comprensión es observarlo desde la actitud.

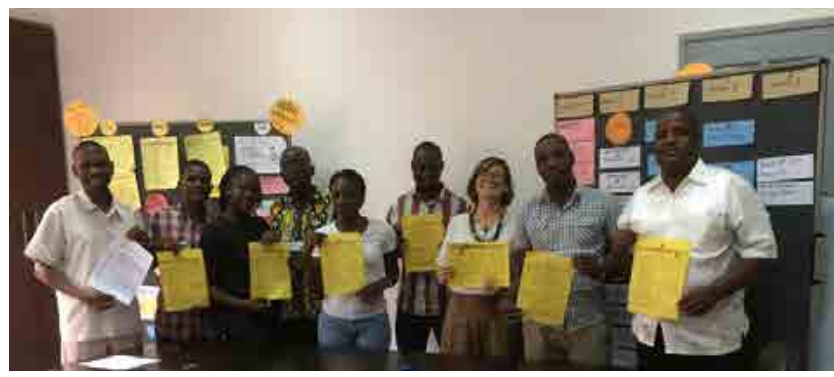

Figura 5. Equipo de operacionalización de la Política de Operación y Mantenimiento de los Edificios Públicos de Mozambique. Fuente: Luis Taremba, 2016. 
En Mozambique se había establecido un acuerdo de cooperación entre dos instituciones: el Ministerio de Obras Públicas y la Agencia de Cooperación Alemana. ${ }^{5}$ El Ministerio de Obras Públicas puso a dos departamentos a trabajar en el objetivo. Cooperación Alemana colocó a dos asesores en dos direcciones provinciales. Para estos últimos el objetivo estaba claro: se trataba de hacer operativa una política pública, a lo largo de un periodo de dos años, siguiendo un método determinado - Capacity Works - . El contexto era desconocido - la manera de ser, pensar y actuar de los funcionarios mozambiqueños con los que se iba a trabajar-. El componente cognitivo estaba condicionado por una falta de conocimientos tanto de cómo operacionalizar políticas como de mantenimiento de edificios. El componente afectivo y emocional se veía afectado por una distancia tanto profesional como vital con el proyecto. Se trataba de un proyecto ligado a temas de legislación y no de construcción, desarrollado en una nueva ciudad y un nuevo país, con nuevos compañeros.

Estas condiciones condujeron a una línea de acción desarrollada a partir de preguntas y respuestas en las que se trataba de incluir a todos los participantes: ¿Los funcionarios con los que se iba a trabajar compartían el mismo objetivo? ¿Contaban con el mismo tiempo para llevarlo a cabo? ¿Tenían la misma motivación? ¿Entendían la diferencia entre asesoría y asistencia técnica? ¿Les interesaba el mantenimiento de edificios? ¿Habían operacionalizado otra política con anterioridad? ¿Tenían otras tareas?

Los funcionarios conocían el objetivo - cognitivamente, y tenían muchos otros-, tenían poca experiencia en mantenimiento de edificios, aunque sí en operacionalizar políticas, afectivamente confiaban en los asesores de cooperación alemana ya que trabajaban con ella desde hacía 10 años. Lo que condujo a una conducta de espera tranquila ante un proceso que llegaba.

5. El Programa de Buena Gobernación Financiera de la cooperación bilateral entre Alemania y Mozambique desarrolló una componente de inclusión de servicios públicos en los presupuestos del Estado de Mozambique entre los que estaba acompañar la operacionalización de la Política de Mantenimiento de Edificios Públicos Decreto $62 / 2011$ 


\subsubsection{Consecuencias del encuentro de los diferentes actores en función de sus actitudes}

No es fácil trabajar para y con las personas. Implica una actitud de escucha, de paciencia, de aceptación de diferencias culturales, de entendimiento de que cada uno primará sus necesidades individuales y que pocos apostarán por el bien común. Equilibrar las necesidades de todos los actores, promoviendo aquéllas con menos fuerza para hacerse escuchar, forma parte del trabajo de quienes facilitamos dichos procesos. Trabajando dentro del ente financiador del proyecto se puede percibir que algunas personas se acercan desde el interés. Sin embargo, obviar la condición humana en este tipo de proceso invita a la frustración.

Cuando se plantea el tema de la actitud, es interesante aceptar que cada uno llega con una actitud determinada y se encuentra con la de los demás. Esa actitud tiene dos niveles, aquélla que reconocemos y aquélla que desconocemos. Ambas afectan nuestra conducta y nuestra forma de interactuar con los demás. Todo ello tiene un impacto en la conducta frente al proceso, en la motivación y en el compromiso.

Tanto los funcionarios como los asesores se veían afectados por los retos inherentes al proyecto: la inseguridad ante un contexto desconocido, la falta de tiempo para desarrollar un programa de estas dimensiones, el exceso de trabajo, la ausencia de motivación política y económica, y el desconocimiento de la lengua. Para la cooperación alemana, operacionalizar la política suponía un modo de alcanzar un objetivo de desarrollo: reforzar capacidades de funcionarios y con ello de instituciones. Para los funcionarios, más trabajo sin más sueldo.

Cognitivamente los funcionarios tenían la creencia de que los expertos sabían cómo iba a ser el proceso; afectivamente, eso les daba seguridad y con ello su conducta era reforzar el compromiso. Parte del método era «prueba/ error». Por parte de los asesores se pusieron en práctica herramientas de participación, se plantearon continuamente preguntas y se facilitaron espacios para que los funcionarios hicieran el trabajo. El trabajo se compartía para que no dejaran de verse resultados, ya que cuando los procesos se alargan demasiado la desmotivación puede frenarlos por completo. 
Después de dos años, se había llegado mucho más allá de los resultados esperados. Se publicó un «libro del edificio», se incluyó el mantenimiento dentro de los presupuestos del estado, se crearon los procesos administrativos, un manual para capacitación de funcionarios, un plan nacional y, sobre todo, se adquirió la conciencia de la importancia del mantenimiento para prestar servicios públicos de calidad. Un hito del proyecto supuso la aprobación por el Consejo del Ministerio del «ABC del mantenimiento», una ficha explicativa muy sencilla, que logró conquistar el proceso en la esfera política. Todos ellos son hitos que refuerzan la motivación.

\subsection{Entendimiento de diferentes contextos: imaginación, inquietud y empatía como herramientas}

Archilla (2008) expone que entre las habilidades a entrenar dentro de una visión disfrutista está la imaginación, que es entre otras cosas la construcción de imágenes. Dicha construcción se agiliza cuantas más imágenes se haya recogido por el camino.

Tener la oportunidad de haber vivido en diferentes contextos y regiones y de haber trabajado en diferentes organizaciones permite ver muchas realidades. Hasta que no se ve y se siente una realidad resulta imposible empezar a comprenderla. Las personas que no han salido de la barriada de Dharavi en India no pueden imaginar un paseo en una ciudad europea, ni los que pasean por bulevares europeos lo que supone recorrer cada día kilómetros en zonas rurales de Cabo Delgado en Mozambique. Ni quienes viven en dichas áreas rurales mozambiqueñas dimensionan la complejidad de una barriada india (fig. 6, 7 y 8). Por muchas herramientas descriptivas que tengamos — video, foto, texto, etc. - sólo estando y viviendo en un lugar se puede sentir y empezar a comprender de forma integral. 

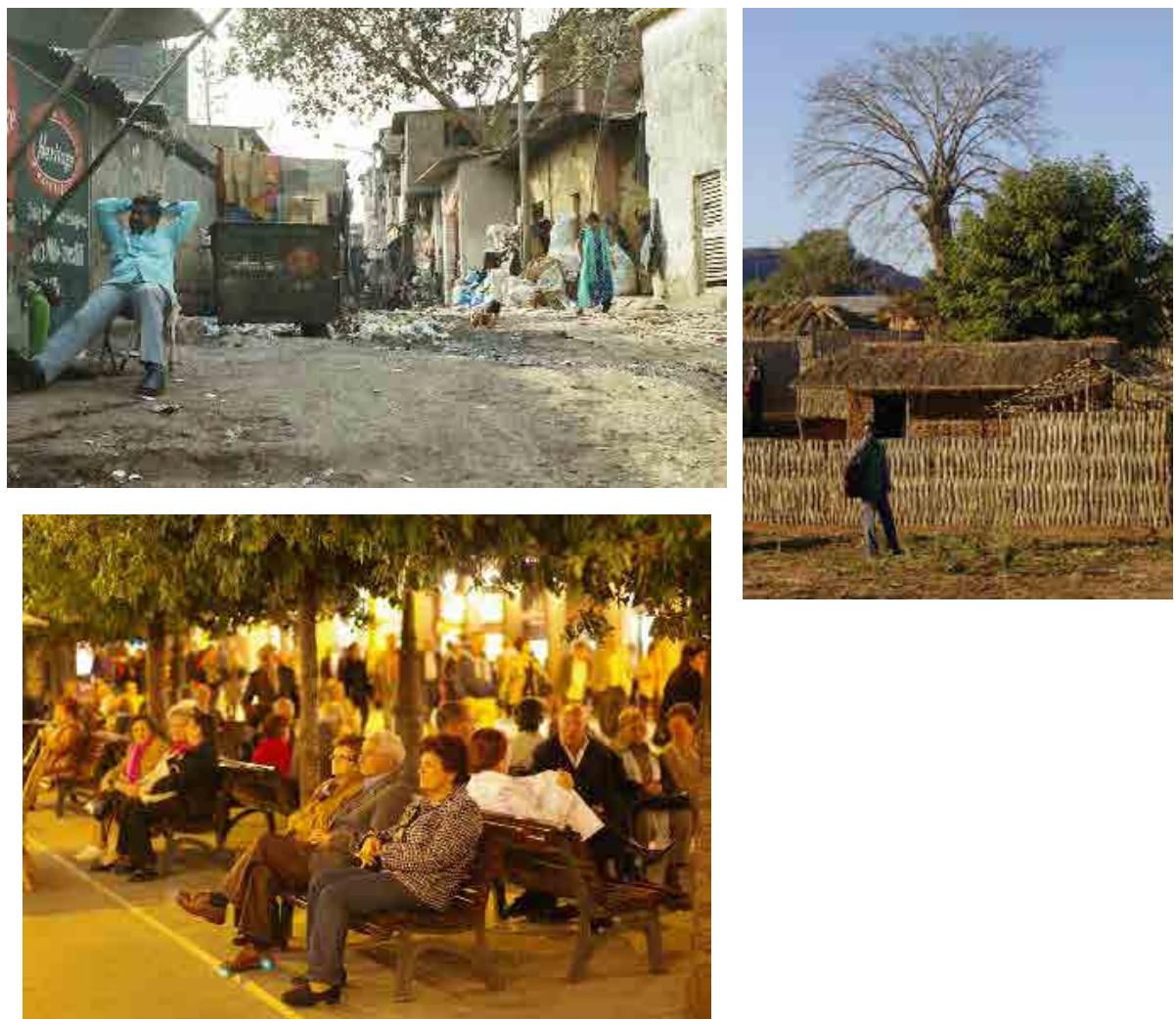

Figura 6, 7 y 8. Barriada de Dharavi, Mumbai, 2008; paseo de Valladolid, España (2011); población en Cabo Delgado, Mozambique (2010). Fuente: autora.

Cuando se habla de la línea de pobreza extrema, cómo vivir con menos de un dólar noventa al día, ${ }^{6}$ es difícil imaginar que estamos hablando de muchas personas concretas, cada una con sus circunstancias (Banco Mundial, 2015). Sólo desde la experiencia se puede comprender la realidad de Sulma, en Venezuela, que comparte su casa-cuarto sin ventanas en un barrio de Caracas; de Doña Ángeles y su antigua cocina de 1,4 m de altura; de Selvi, en Kalijanpoondi, que sale cada día a mendigar. Desde la experiencia se puede observar una realidad global donde la desigualdad, la pobreza y la falta de oportunidades imperan.

6. Diferentes instituciones establecen parámetros para medir la pobreza. Se toma el del Banco Mundial sólo para dar una cifra y poner de relieve que detrás de esas cifras invisibilizan a las personas. http://www.bancomundial.org/es/topic/poverty/brief/global-poverty-line-faq 
De los casos concretos se puede deducir que, en los contextos rurales, la falta de acceso a servicios se incrementa, mientras que la miseria puede suavizarse al contar con un poco más de espacio para plantar. Entre los problemas con los que se enfrentan los ejidatarios de Santa María de Cocos (México) están las políticas asistencialistas y la presión para que dejen de cultivar y con ello perder sus tierras para las grandes corporaciones.

La problemática de la movilidad urbana puede servir de ejemplo, por lo que afecta a muchas de las personas implicadas en estos proyectos. En Maputo, la movilidad ahora está reducida a un sistema público-privado deficitario que no garantiza ni la dignidad, ni la seguridad (hacinamiento, atropellos, esperas, desinformación, etc.); la bicicleta, además de suponer un riesgo, está asociada a la pobreza; sólo queda caminar o los automóviles, que a pesar de transportar a la minoría tienen absoluta prioridad.

Para quien no lo haya experimentado es difícil de entender, por ejemplo, lo que supone transportarse en una «chapa» - furgoneta de 14 puestossiendo 20, o en «mylove» - camiones que transportan ilegalmente a personas en horas punta - . Tienen un componente de aventura incluso la primera vez. Tener una visión global implica entender que la mayoría de las personas con las que se trabaja en Maputo llegaron en «chapas». Estas personas estuvieron esperando, hacinándose, recuperando la compostura y que cuando acaben su jornada laboral volverán a moverse igual. Hamilton amanece a las cuatro para llegar a la oficina a las 8 después de dos «chapas». ¿Puede tener la misma actitud que quien llega caminando tras un paseo o en su coche?

Las personas se adaptan a su contexto, cuando moverse es difícil, hay menos comida de la necesaria, los hospitales no responden a las necesidades de una población, el salario de la policía conduce a que abusen de la población, etc., las personas con las que se realizan los proyectos tendrán otras prioridades. La empatía se impone como una de las herramientas fundamentales a la hora de compartir espacios vitales y profesionales en estos contextos.

Incluso en las ONGD el personal que trabaja en las sedes europeas acompañando el trabajo en terreno puede no entender por qué todo va tan despacio sobre el terreno. 


\subsection{Necesidades de cambio eco-social}

Una vez analizada la actitud ante la profesión en los casos cabe preguntarse si es posible extrapolar el impacto de la actitud para generar un cambio social. Cabe preguntarse si ese cambio debe quedar reducido a centrarse en las personas ignorando los límites del planeta. La Gran Encrucijada (Herrero, Prats y Torrego, 2017) describe de manera tajante la crisis ecológica global y la necesidad de un cambio de paradigma. Resulta difícil imaginar que un sistema capitalista patriarcal y global, que ha conducido a esta situación, tenga la capacidad de desarrollar un cambio en el plazo necesario. ¿Cómo puede la actitud además de centrarse e incluir a las personas considerar los límites del planeta?

\section{Discusión de los resultados}

\subsection{Toma de decisiones en procesos participativos}

Cada uno de los actores tenemos sueños, deseos, necesidades, valores, intenciones, motivación, compromisos, etc.; cada uno de los actores tenemos una actitud (fig. 9). Cuando los procesos son participativos se incluyen más actores en la toma de decisiones. Los procesos pasan a ser más lentos y complejos si se comparan con los procesos autoritarios o los que ignoran a los actores que no ostentan el poder.

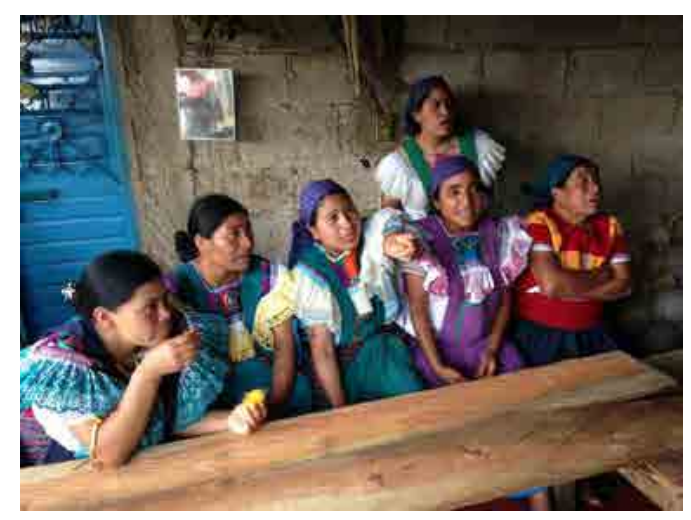

Figura 9. Programa vacA, diferentes actitudes durante los procesos de diseño participativo en Amatenango del Valle, 2016. 
No existe un modelo único de proceso participativo. En ninguno de los incluidos en este artículo tienen todos los actores la misma capacidad de decisión —implicación, apropiación, conocimiento técnico, etc.—. La inclusión no implica que todos tengan el mismo peso en todas las decisiones, sino que todas las posturas se tengan en cuenta y se organicen los diferentes tipos de decisión. Hay decisiones exclusivamente técnicas. Hay decisiones ligadas a las necesidades de una comunidad: en ellas, nadie mejor que cada uno de sus miembros debería tener voto.

El papel de los técnicos ahí puede ser el de crear imaginación o promover la voz de quienes no consiguen hacerse oír. Por ejemplo, en Izúcar de Matamoros, la familia Sánchez no tenía un baño que garantizase la intimidad y por tanto hacía más vulnerables a las niñas y niños de la familia. La cocina no permitía extraer el humo y medía $1,4 \mathrm{~m}$. Seis niños dormían en la misma cama. Durante el proceso de diseño con la familia, se pudo ver que los padres no pensaban que una cama para cada niño era importante, la madre sí quería una cocina alta, pero no tenía miedo del humo (ni conciencia de las enfermedades respiratorias), el padre quería una casa de bloque como la de sus vecinos pero no le daba importancia al baño, a la hija de 18 años sí le importaba poder cerrar la puerta cuando fuera al baño...

La intención, explícita u oculta, de cada uno de los actores hacia materializar viviendas, espacios públicos, infraestructuras, espacios culturales, plazas, define el nivel de equilibrio de los asentamientos resultantes. Los procesos participativos de hacer ciudad o asentamientos rurales son lentos y están abiertos. Implican muchas decisiones. En cada decisión se produce un doble proceso de negociación. Primero, a nivel individual cada actor considera sus valores, necesidades y circunstancias en ese instante y en el futuro. Segundo, en la interacción con el conjunto (fig. 10). Equilibrar ambos niveles puede garantizar la calidad de las decisiones. 


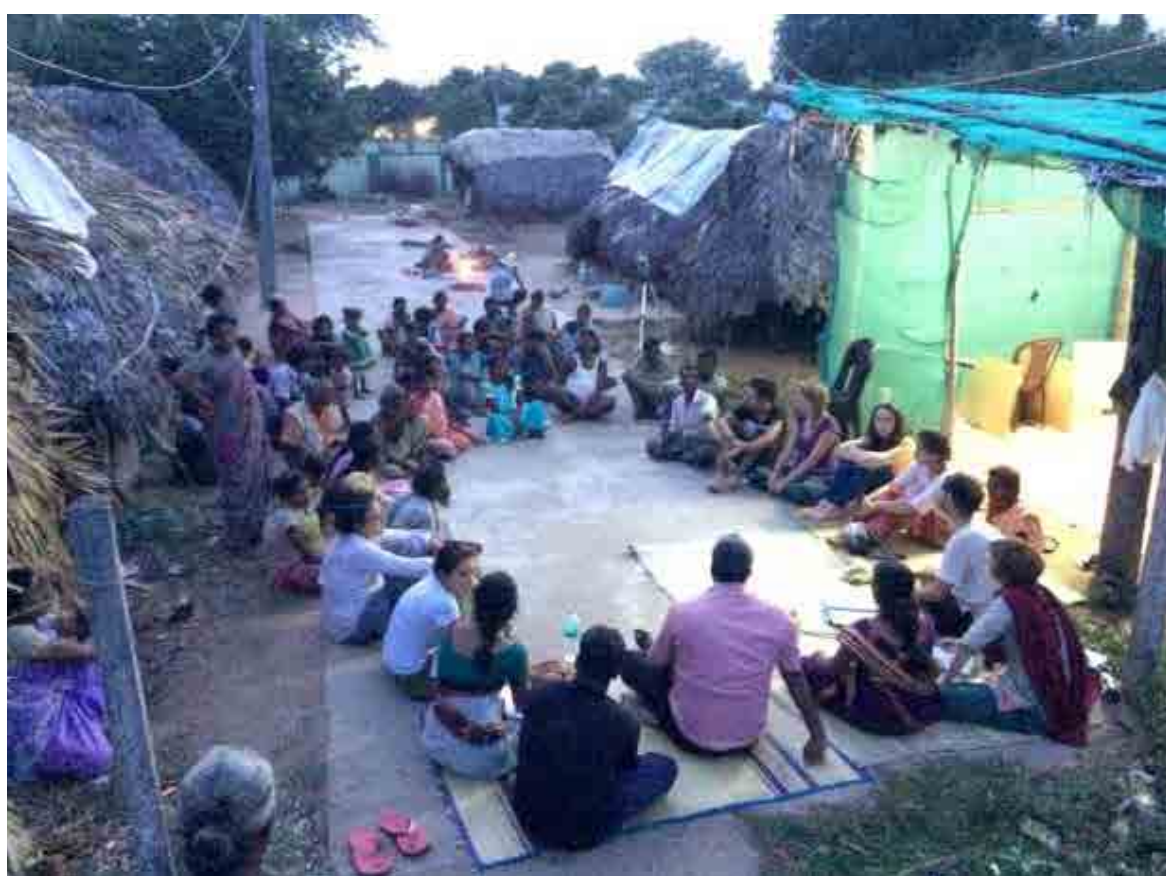

Figura 10. Programa vaCA, diseño participativo en Kaliyanpondi, India, 2016.

Los actores de la cooperación al desarrollo están acostumbrados a trabajar estructurando desde «misión y valores». Human building no implica necesariamente trabajar en un marco de valores considerados positivos por quienes participan sino, primero, encontrar lugares comunes a través de una negociación en la que todas y todos ganamos (win-win) para después cumplir y ser coherentes con esos compromisos a través de la acción.

En Niamey, los directores y directoras de los centros culturales desarrollaron los criterios para evaluar las propuestas de los artistas para crear una agenda cultural. Durante el proceso de selecciones se aprobaron y rechazaron cambios en los criterios de forma consensuada para adaptarse a las propuestas recibidas. Estos procesos sólo requieren rigidez con el cumplimiento de los compromisos. Los participantes pueden revisar, renegociar y volver a establecer nuevos compromisos posteriormente. 
3.2 Estrategias eco-sociales para desarrollar asentamientos humanos para y con las personas

Harvey (2003) mantiene que el derecho a la ciudad va más allá del acceso a la vivienda, las infraestructuras y servicios públicos; debe implicar el derecho a cambiar la ciudad. ¿Qué sucedería si este derecho fuera aún más inclusivo y considerara otros territorios habitables como las áreas rurales?, ¿qué sucedería si el derecho a cambiar la ciudad y las áreas rurales resultara de la suma de vivencias de individuos conscientes que buscan el bien común sin ignorar el impacto en un ecosistema finito?

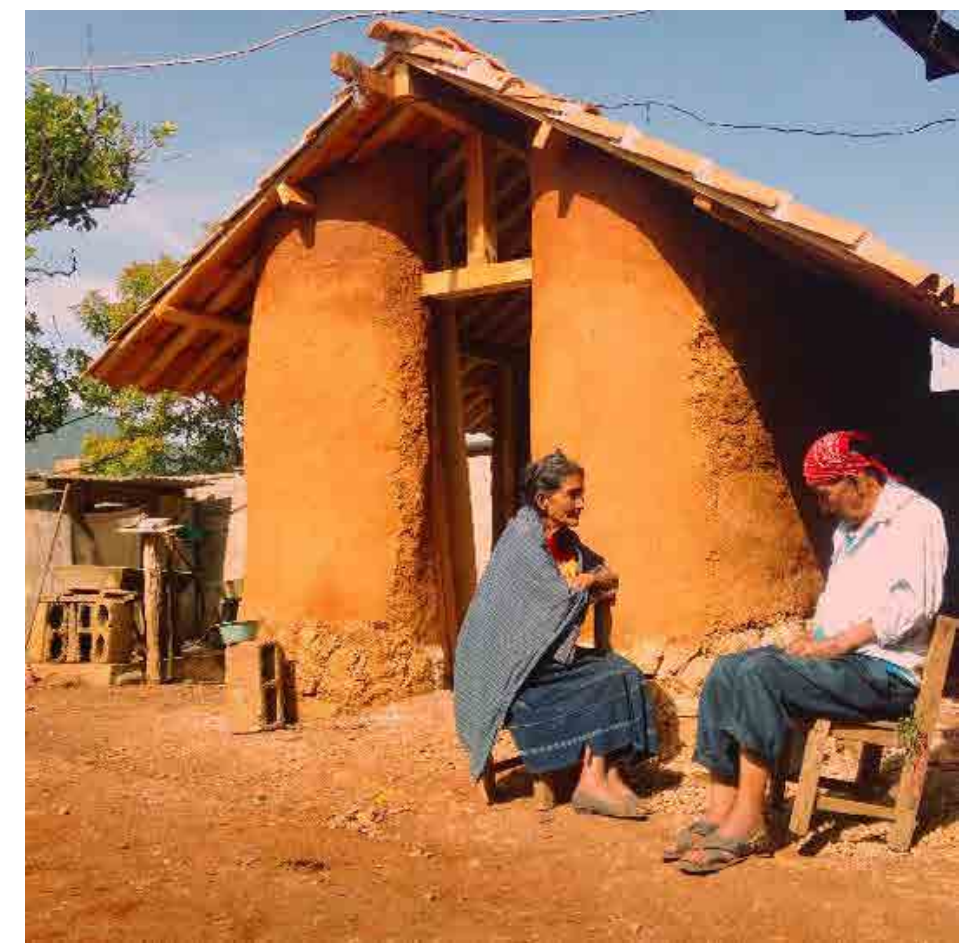

Figura 11. Programa vaca, teoría del bien común promovida por diferentes grupos indígenas de Latinoamérica, México, 2016.

Los proyectos incluidos en este artículo se circunscriben tanto a escala nacional como local. Cada uno tiene un sentido. Poder conectar proyectos que empiezan desde lo local hacia lo global con aquellos que van desde lo global a lo local reforzará un cambio eco-social. Civic Wise trabaja desde hace varios años con proyectos en red combinando ambas escalas en intervenciones glo- 
cales. ${ }^{7} \mathrm{El}$ resultado son personas trabajando para sus ciudades o áreas rurales conectadas entre sí en un intercambio continuo de experiencias que enriquece los procesos.

Existe una relación entre las teorías del bien común — promovidas por pueblos indígenas en Latinoamérica (fig. 11) — y la teoría del decrecimiento de Latouche. Ambas defienden la importancia del cambio eco-social que incluye a las minorías y plantea la suma de muchos sistemas en equilibrio con el medio. Ambas niegan el crecimiento ilimitado.

\subsubsection{Factores que influyen positivamente en la actitud individual: apropiación, disfrute, compromiso y belleza}

Lejos de plantear como únicas posibles soluciones las adoptadas en los proyectos descritos, sí se puede defender la actitud como denominador común de todos ellos. Ni siquiera es un continuo de «problema-solución», sino un conjunto de acciones que incluyen llegar a un lugar, conectar con las personas, observar el ecosistema y comenzar a pensar estrategias. Para eso hacen faltan técnicos con una determinada actitud. El programa VACA fue dibujando esa actitud con la práctica.

La apropiación, al igual que la actitud, forma parte de los factores que aumentan la probabilidad de que los procesos generen cambios positivos para las comunidades a largo plazo. Tiene un gran impacto en la durabilidad de los proyectos; cuando la comunidad autoconstruye sus viviendas, aprende a mantenerlas y el ciclo de vida de esos materiales se prolonga. La misma cantidad de recursos puede durar más en las comunidades donde se ha dado la apropiación.

En las cinco ediciones del programa VACA incluidas en el artículo, a lo largo de la construcción realizada junto con las comunidades, se fueron desvelando factores que influían positivamente en la apropiación de los proyectos. Entre ellos el disfrute, el compromiso y la belleza fueron los más significativos, llegándose al punto en el que la belleza tenía el mismo peso que los cinco cri-

7. Civic wise es una red abierta que promueve el compromiso ciudadano desarrollando acciones concretas y proyectos basados en inteligencias colectivas, innovación cívica y diseño público. https://civicwise.org/es/ 
terios de la habitabilidad básica — acceso a saneamiento, agua, durabilidad, falta de hacinamiento y tenencia- (Barrera, Loyo, Márquez y Morán (2014). La actitud frente a la belleza está ligada cognitiva y emocionalmente a la identidad. La belleza de los espacios construidos puede reforzar la identidad de individuos y colectivos empoderándolos para participar en las decisiones que conciernan a sus asentamientos. También se pudo observar que una actitud de disfrute promovía una conducta inquieta, empática, más abierta y flexible hacia el grupo, reforzando la interacción y el trabajo comunitario.

3.2.2 Factores que influyen en decisiones comunitarias: uso de técnicas vernáculas y técnicas adecuadas para todos los miembros de la comunidad.

La identidad y autoconfianza resultaron esenciales en estos proyectos, y también lo fue el empleo de técnicas vernáculas de construcción. Utilizarlas supone construir aprovechando procesos históricos de prueba y error para adaptarse a las condiciones ambientales y las soluciones bioclimáticas más sencillas. Esas técnicas son, por ejemplo, mezclar conglomerados como la cal en dosis pequeñas dando tiempo al agua a permear; la carga a través del hormigueo, nudos que priman el rozamiento frente a la fuerza, etc. Descubrir y mejorar las técnicas más adecuadas para cualquier género y edad demostró reforzar el papel que cada miembro jugaba en su comunidad (fig. 12, 13, 14, 15 y 16). Cuando la obra deja de ser un espacio de lucro y sólo busca dar respuesta a las necesidades habitacionales y sociales, caben todos los miembros de una comunidad, desde la infancia hasta la vejez, con independencia de su sexo y sus capacidades.

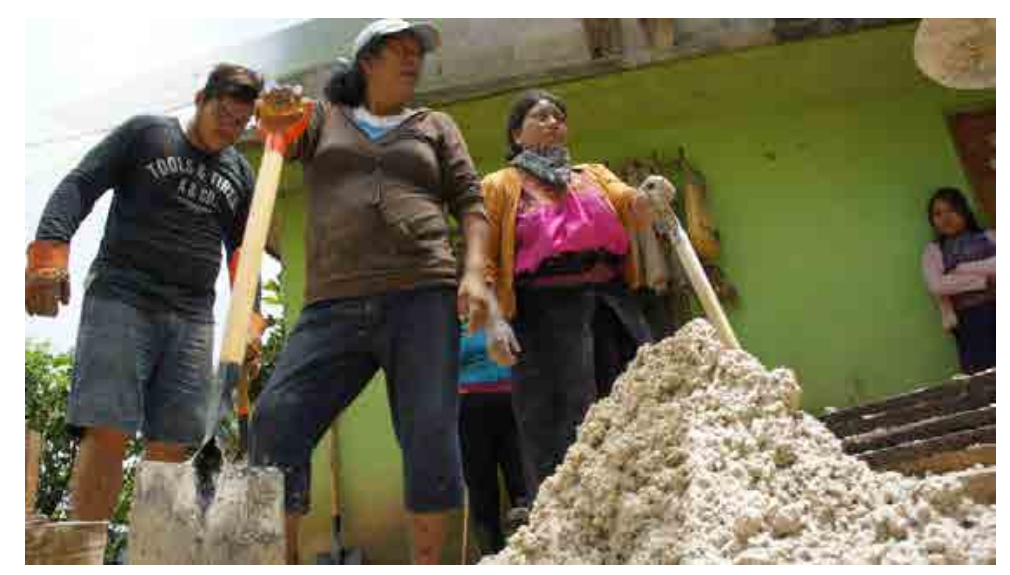



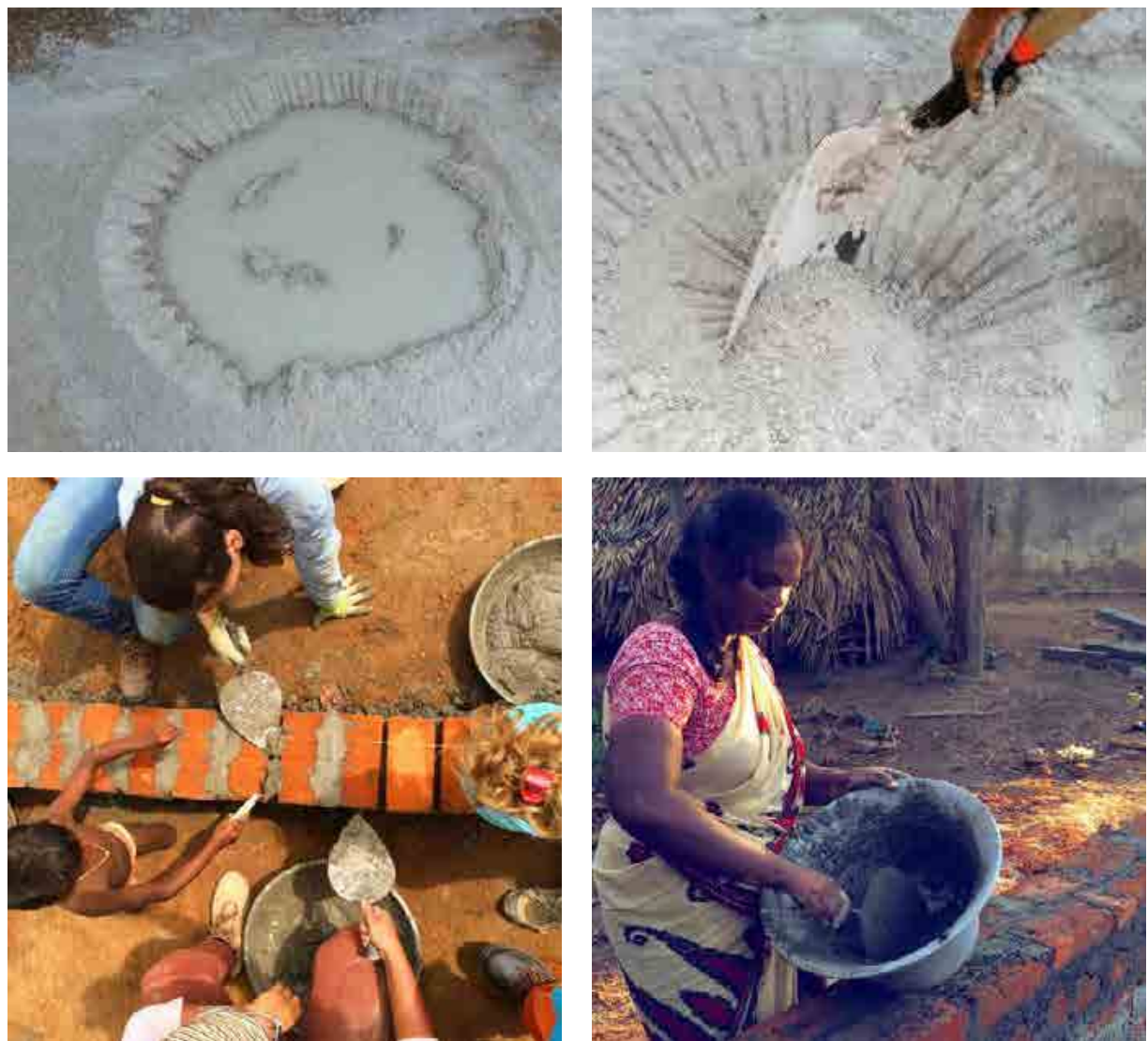

Figuras 12, 13, 14, 15 y 16. Programa vaCA, técnicas adecuadas a cada participante de las obras, 2013-16.

En un principio el uso de técnicas vernáculas y materiales naturales era complejo porque los técnicos y las comunidades tenían visiones diferentes y actitudes enfrentadas. Los técnicos, los defendían desde el conocimiento, las comunidades los rechazaban, emocionalmente, por percibirlos ligados a la pobreza que querían dejar atrás. Luchar contra el rechazo de dichas técnicas parecía no respetar la decisión de la comunidad. Sin embargo, cuando los técnicos consiguieron entender y empatizar con este rechazo pudieron comprender que la decisión se quedaba en el componente emocional, con independencia de los argumentos cognitivos. Así, pudieron aportar un argumento emocional a su vez - la arquitectura con materiales naturales y técnicas vernáculas es de la máxima calidad y belleza - y ello permitió a las comunidades decidir nuevas opciones. Trabajar desde la empatía ayuda a superar obstáculos. 


\subsubsection{Impacto de valorar el bien común por encima del individual}

El proyecto del equipo de Arquitectura Sin Fronteras en el barrio informal de Chamanculo $\mathrm{C}$ en Maputo, iniciado por Ana Cubillo y continuado por la autora, es un ejemplo de recualificación urbana. Las migraciones consecuencia de la guerra densificaron el barrio hasta casi hacer desaparecer las calles. La tenencia a través de la concesión del Dereito ao uso e aproveitamento da terra, DUAT, sólo se tramita para las parcelas con acceso directo a calles, que tienen que tener una dimensión mínima. El reto imposible era que los vecinos devolvieran espacio «tomado» a la calle, y valoraran el espacio público sin tener ninguna compensación económica.

Valorar el bien común por encima del bien individual no parece formar parte de la condición humana de manera natural. ¿Cuál es la actitud que podría promover un cambio semejante? Cognitivamente, durante la fase de sensibilización previa se plantearon mejoras como la posibilidad del acceso al transporte rodado, junto con la eliminación de recovecos en el trazado de las calles que, al facilitar una mejor visibilidad, proporcionarían una sensación de mayor seguridad. Emocionalmente, el impacto hacia la sensación de seguridad y consecuente ganancia de libertad para las mujeres del barrio sería fundamental. Más difícil resultaría la toma de conciencia sobre la mejora de la salubridad ligada al aumento de la ventilación, al incrementar el ancho de las calles.

Resulta difícil imaginar que estos factores no fueran suficientes para apoyar un proyecto de bien común. La actitud de la comunidad fue en principio incrédula, ya que otros proyectos habían prometido y no habían cumplido. Además, estaba el hecho de tener que ceder sin compensación económica. Poco a poco, algunas familias decidieron apoyar el proyecto. La primera fase abrió tres calles y sobre todo mostró que era posible. En la segunda fase la actitud era de confianza. La negociación, el acuerdo y la coherencia frente a los compromisos establecidos pueden ser el motor de la confianza y la apropiación de los asentamientos humanos.

Uno de los elementos más complejos cuando se trabaja para erradicar la pobreza es que los actores no tienen ni tiempo, ni recursos para parar el ritmo de supervivencia y apostar por proyectos que pueden mejorar su situación. En Kalijanpoondi, India, la comunidad mendicante se organizó para auto- 
construir su centro comunitario y continuar mendigando por turnos porque no podía parar durante siete semanas y garantizar la alimentación de sus familias.

Hamilton, el sociólogo del equipo Arquitectos sin Fronteras, que tarda 3 horas en llegar al trabajo, insiste en que las obras se planifiquen para no afectar el ganha pão, sustento, de las familias. Por ejemplo, no construir un muro donde estaba el gallinero hasta que se mueva el gallinero. Este tipo de decisiones en obra han construido la simbiosis entre el bien común — la calle- y el bien familiar — cada parcela— - La actitud de las familias y líderes comunitarios en esta segunda fase es la de apoyar.

El hecho de que Hamilton sufra el transporte y trabaje en proyectos de cooperación viene a poner en evidencia la importancia de entender a las personas en sus numerosas dimensiones y circunstancias. Una actitud empática, conocer la realidad del otro e imaginar lo que siente, lleva a lugares de encuentro en las negociaciones.

\section{Conclusión: promover la actitud de construir para y con las personas}

Mirando atrás, el hilo conductor de estos seis casos ha sido enfocarlos para y con las personas, hasta ahora desde la intuición, a partir de ahora desde la consciencia.

Después de observar bajo el prisma de la actitud los proyectos realizados, se pone de relieve el movimiento hacia cambios eco-sociales, dado el poderoso impacto que éstos han tenido en las personas que participaron.

Una actitud empática, de disfrute y compromiso ante el diseño, la construcción, el mantenimiento, la enseñanza, el marco legislativo, las políticas públicas y la gestión de proyectos ha promovido participación y apropiación en los casos presentados. Con ello se incrementa la posibilidad de mantener lo construido, de aumentar los ciclos de vida y de encontrar equilibrios con el ecosistema limitado.

Trabajar y vivir para y con las personas, como se ha mencionado, no implica no poder abstraer utilizando estadísticas cuando se formulan proyec- 
tos. Implica saber cuándo abstraer para que los proyectos avancen y cuándo involucrar a cada una de las personas.

La participación es profundamente compleja y no debe ignorar la condición humana. Una actitud que reduce las expectativas y que aporta imágenes que construyen imaginación, ejemplos, cuentos e información facilita decisiones inclusivas.

Human building —un concepto clave para entender esta visión de la participación - busca encontrar lugares comunes a través de una negociación en la que todas y todos ganamos (win-win), para después cumplir y ser coherentes con esos compromisos a través de la acción. Negociación, acuerdo y coherencia ante los compromisos establecidos son el motor de la confianza y la apropiación de los espacios construidos, y con ello el mantenimiento y la durabilidad. Estos procesos sólo requieren un respeto total a los compromisos. En cualquier momento los participantes pueden revisar, renegociar y volver a establecer nuevos compromisos.

El estado mental de consciencia social y personal mantenido en los casos analizados condujo al desarrollo de una actitud que benefició a las personas y a sus ecosistemas (fig. 17). Todo lo anterior nos lleva a la propuesta de observar la actitud como vector transversal en futuros proyectos para hacer los asentamientos humanos más humanos.

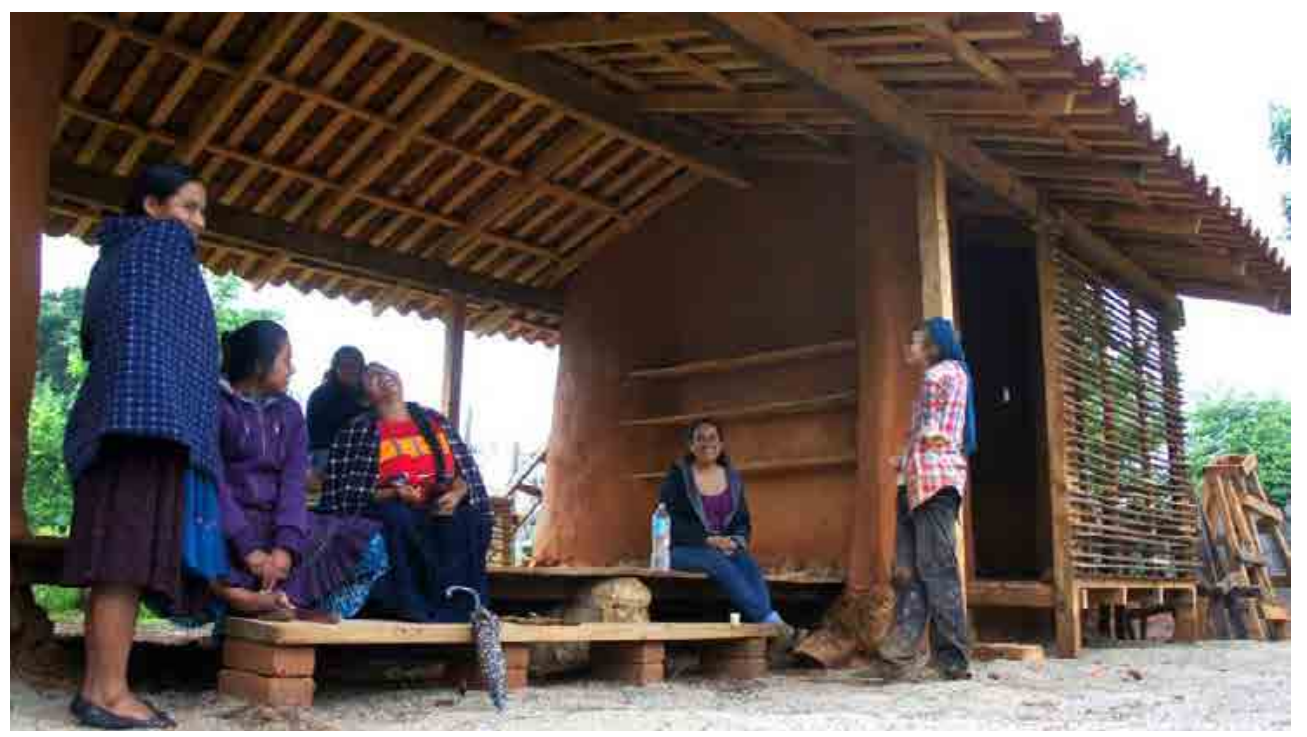

Figura 17. Programa vaCA, compromiso y disfrute, 2013-16. 


\section{Referencias}

Anderson, J. \& Priest, C. (2012). «Developing a Live Projects Network and Flexible Methodology for live projects». Paper presented at the Live Projects Pedagogy International Symposium 2012, Oxford Brookes University, May 2012.

Archilla, D. (2008). Metodología del disfrute: cinco habilidades a desarrollar en el proceso. Madrid: Tesis Doctoral, Departamento de Proyectos Arquitectónicos, Escuela Técnica Superior de Arquitectura de Madrid.

Banco Mundial (2015). Población rural. Recuperada en marzo de 2017 de https://datos.bancomundial.org/indicador/SP.RUR.TOTL.ZS

Banco Mundial (2015). Línea de pobreza extrema. Recuperada en noviembre de 2017 de http://www.bancomundial.org/es/topic/poverty/brief/ global-poverty-line-faq

Barrera, A., Loyo, J., Marquez, S. \& Morán, T. (2014). «Programa vacA: aprendizaje, compromiso y disfrute para la superación de la pobreza utilizando como herramientas la recuperación de técnicas vernáculas y el empoderamiento constructivo comunitario». III Jornadas de Arquitectura y Cooperación ArCaDia III. Recuperado en marzo de 2017 de https://programavaca.files.wordpress.com/2015/04/comunicacion_jornadas-arcadiaiii_programa-vaca.pdf

Briñol, P., Falces, C., \& Becerra, A. (2007). «Actitudes». En Psicología social (pp.457-490). España: McGraw-Hill. Recuperada en marzo de 2017 de https://www.uam.es/otros/persuasion/papers/Actitudes. pdf

Di Siena, D. (2009). Espacios Sensibles. Hibridación físico-digital para la revitalización de los espacios públicos. Pp. 218-220 Madrid: Programa de Doctorado Periferias, sostenibilidad y vitalidad urbana. Escuela Técnica Superior de Arquitectura de Madrid. Recuperada en marzo de 2017 de http://urbanohumano.org/download/Espacios_ Sensibles_15.09.09.pdf

GIz (2009). Capacity WORKS. NEPAD Agency (marzo 15, 2017): http://www. africa-platform.org/sites/default/files/resources/Capacity_WORKS-Management_Model_2012.pdf 
Harvey D. (2003). «The Right to the City». International Journal of Urban and Regional Research, 27: 939-941. DoI:10.1111/j.03091317.2003.00492.x

Latouche, S. (2004). Degrowth economics. Recuperado de Le Monde Diplomatique (marzo de 2017): http://www.jussemper.org/Resources/ Economic\%20Data/Resources/Degrowth\%20economics, $\% 20$ by $\% 20$ Serge $\% 20$ Latouche.pdf

ORGANIZACIÓN DE LAS NACIONES UNIDAS (2016). Nueva Agenda Urbana, UN-Habitat. Recuperada en Diciembre de 2016 de: http://habitat3.org/wpcontent/uploads/Draft-Outcome-Document-of-Habitat-III-S.pdf

Organización de LAS NaCIONES UNIDAS (2007). Estado de la población mundial 2007. UNFPA. Recuperada en marzo de 2017 de https://www. unfpa.org/sites/default/files/pub-pdf/swp2007_spa.pdf

SAmra, R. (2014). «A New Look at Our Old Attitude Problem». Journal of Social Sciences, 10(4), pp.143-149. Dor: 10.3844/jssp.2014.143.149. Recuperada en marzo de 2017 de http://thescipub.com/PDF/ jssp.2014.143.149.pdf 
